BMJ Open

Diabetes

Research

\& Care

\title{
Higher health literacy is associated with better glycemic control in adults with type 1 diabetes: a cohort study among 1399 Danes
}

Kasper Olesen, ${ }^{1}$ Anne Louise F Reynheim, ${ }^{1,2}$ Lene Joensen, ${ }^{1}$ Martin Ridderstråle, ${ }^{1,3}$ Lars Kayser, ${ }^{2}$ Helle T Maindal, ${ }^{1,4}$ Richard H Osborne, ${ }^{2,5}$ Timothy Skinner, ${ }^{1,6}$ Ingrid Willaing ${ }^{1}$

To cite: Olesen $\mathrm{K}$,

F Reynheim AL, Joensen L, et al. Higher health literacy is associated with better glycemic control in adults with type 1 diabetes: a cohort study among 1399 Danes. BMJ Open Diab Res Care 2017;5:e000437. doi:10.1136/ bmjdrc-2017-000437

Received 8 May 2017 Revised 25 July 2017 Accepted 28 July 2017

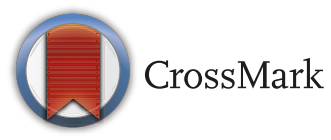

${ }^{1}$ Steno Diabetes Center Copenhagen, Gentofte, Denmark

${ }^{2}$ Department of Public Health, University of Copenhagen, Copenhagen, Denmark ${ }^{3}$ Novo Nordisk A/S, Søborg, Denmark

${ }^{4}$ Department of Public Health, Section for Health Promotion and Health Services, Aarhus University, Aarhus, Denmark ${ }^{5}$ Health Systems Improvement Unit, Deakin University Centre for Population Health Research, Geelong, Australia

${ }^{6}$ Charles Darwin University, School of Psychological and Clinical Sciences, Darwin, Australia

Correspondence to Kasper Olesen, Steno Diabetes Center Copenhagen, Niels Steensens Vej 6, 2820, Gentofte, Denmark; kasper.olesen@regionh.dk

\section{ABSTRACT}

Aim Self-management of diabetes is influenced by a range of factors including the ability to access, understand, appraise, and use of health information in everyday life, which can collectively be called health literacy. We investigated associations between nine domains of health literacy and HbA1c level in people with type 1 diabetes. Methods A cross-sectional study was conducted with 1399 people with type 1 diabetes attending a Danish specialist diabetes clinic. Health literacy was assessed using the nine-domain Health Literacy Questionnaire. The association between health literacy and $\mathrm{HbA} 1 \mathrm{C}$ was analyzed using linear regression with adjustment for age, sex, educational attainment and diabetes duration. Results Of the 1399 participants, $50 \%$ were women, mean age was 54 years, and mean $\mathrm{HbA} 1 \mathrm{c}$ was $61 \mathrm{mmol} /$ $\mathrm{mol}(7.8 \%)$. Higher health literacy scores were associated with lower $\mathrm{HbA} 1 \mathrm{C}$ levels across eight of nine health literacy domains. This association remained significant after adjusting for educational attainment. Among the domains, 'Actively managing my health' had the strongest impact on HbA1c. This was in turn predicted by 'Appraising health information', 'Having sufficient information to manage health', and 'Social support for health'.

Conclusions Higher health literacy levels are associated with lower HbA1c regardless of educational background. This study highlights the importance of healthcare provision to respond to the health literacy levels of people with diabetes and to the possible need to provide program designed to enhance health literacy.

\section{INTRODUCTION}

Self-management of type 1 diabetes is a complex and demanding task, drawing on time as well as cognitive and emotional resources of the individual. ${ }^{1}$ Using these resources effectively and efficiently requires individuals to engage with healthcare professionals regularly to update and adjust knowledge and skills and to learn how to use new technologies and devices. ${ }^{2}$ Therefore, understanding health information and successful communication with healthcare providers is crucial for

\section{Significance of the study}

What is already known about this subject?

- Health literacy has increasingly been recognized as critical to an individual's resources and capability to self-manage chronic conditions such as type 1 diabetes.

What are the new findings?

- Higher health literacy levels are linearly associated with lower $\mathrm{HbA1C}$ in this large population of people with type 1 diabetes.

- Educational attainment seems to play a minor role in the associations between health literacy and $\mathrm{HbA} 1 \mathrm{c}$ level.

How might these results change the focus of research or clinical practice?

- Effective interventions to enhance health literacy in people with type 1 diabetes have potential to improve active self-management and glycemic control.

self-management for people with diabetes. The skills of understanding, appraising and engaging with health information is also important outside the relationships with the diabetes care team, not least with increasing information available through the internet and social media. ${ }^{3}$ Although guidelines and standards for the comprehensibility of health information and resources are being defined worldwide, research continues to demonstrate that much of the available health information does not meet these standards. ${ }^{4}$

In this context, health literacy is increasingly recognized as critical to our understanding of an individual's resources and capability to selfmanage chronic conditions. Health literacy is defined as the 'cognitive and social skills which determine the motivation and ability of people to gain access to, understand and use information in ways which promote and 
maintain good health'. ${ }^{5}$ Previous studies on the importance of health literacy in diabetes management have been inconsistent. ${ }^{6-8}$ Some studies have found an association between low health literacy and low HbAlc level, ${ }^{9-12}$ whereas others did not find such association. ${ }^{13-16}$ One reason for the lack of consistency may relate to differences in measurement of health literacy, for example, use of measures that focus on health-related literacy and numeracy (ie, functional health literacy), rather than the wider range of competencies that are necessary for diabetes self-management. We use a multidimensional measure of health literacy, including ability to read, understand, and critically appraise health information and ability to navigate the health system, communicate and engage with healthcare providers. This measure offers the opportunity to explore the relationship between health literacy and diabetes management with greater precision.

Another challenge in the literature on healthy literacy is that the use of measures of literacy commonly report strong associations between patient characteristics, including educational attainment, income and health literacy. ${ }^{3}$ This is problematic as it makes it unclear whether the measurement used to asses health literacy is just a proxy measure of educational attainment, or contributing uniquely to the understanding of the challenges of diabetes self-management and people's engagement with the healthcare professionals and educational resources. A recent study has suggested that health literacy mediates the association between educational attainment and health behavior in people with diabetes. ${ }^{17}$ However, few studies have examined the relationship between health literacy and health outcomes across different socioeconomic groups. Thus, we sought to explore whether health literacy was associated with self-management and outcomes across different socioeconomic groups.

In addition, the majority of previous studies of health literacy and diabetes management have focused on people with type 2 diabetes; however, knowledge about health literacy and HbAlc among people with type 1 diabetes remains scarce and inconsistent. Therefore, we sought to investigate the association between each of the nine domains of the Health Literacy Questionnaire (HLQ) and HbA1c level in a large population of people with type 1 diabetes. We hypothesized that higher health literacy was independently associated with lower levels of HbAlc as a marker for HbAlc level and that this result would be consistent across groups with different levels of educational attainment.

\section{RESEARCH DESIGN AND METHODS}

\section{Study population}

In May 2014, we invited all people receiving care at a specialist diabetes clinic in Denmark to participate in the study. A questionnaire was sent to all potential participants. Participants were informed that they could also complete the questionnaire online. Non-responders received a reminder after 1 month, and potential participants with a visual impairment registered in the electronic patient record were contacted by phone and offered assistance to complete the questionnaire. Among 3167 invited people with type 1 diabetes, 1425 (45\%) agreed to participate and completed the questionnaire. Following written consent, we linked questionnaire data to individual electronic patient records using a unique identification code. Due to insufficient data on key variables, 26 people (2\%) were excluded, leaving a study population of 1399 participants.

\section{Assessment of health literacy}

Health literacy was assessed using the Danish version ${ }^{18}$ of the HLQ ${ }^{19}$ This instrument has been translated to over 20 languages and applied in over 30 countries. The HLQ consists of nine individual scales, each with four to six items (44 across all scales). Scores for each scale were calculated for each respondent as the mean scores of the four to six items comprising the scale. If responses were missing on up to half of the items in a scale, the mean of the remaining items was used to replace missing values. If more than half of the items were missing, the entire scale was regarded as missing. ${ }^{20}$ The response option for scales 1-5 ranged from 1 (strongly disagree) to 4 (strongly agree), whereas scales $6-9$ were rated on a scale that ranged from 1 (cannot do) to 5 (very easy).

\section{Assessment of HbA1c level}

HbAlc values $(\mathrm{mmol} / \mathrm{mol}$ ) were routinely obtained and recorded in the electronic patient record using routine clinical measurement methods at each clinic visit in the cohort under study, approximately every 3-4 months. To diminish potential effects of seasonal variation, ${ }^{21}$ the mean of all available values for the past year (median number of measures used $=3$ ) was used for each participant.

\section{Assessment of other variables}

Information on sex, age, diabetes duration, body mass index (BMI), and registered visual impairment was obtained from the electronic patient record. Age and diabetes duration were included in the models as continuous variables. Information on educational attainment was obtained from self-reported questionnaires, in six categories: primary school only, vocational school, higher education ( $<3$ years), higher education (3-4 years), higher education ( $\geq 5$ years), and a category comprising 'other' and missing data.

\section{Statistical analyses}

Descriptive statistics were used to analyze characteristics of the study population:sex, age, diabetes duration, educational attainment, BMI and HbAlc. Analysis of non-responders was carried out based on the available data from the electronic patient records. Non-responders were compared with the study population on sex, age, diabetes duration, BMI and HbA1c. To investigate the associations between the health 
literacy scales and HbA1c levels, multiple linear regressions were applied with each scale as independent variable and HbAlc level as the outcome. Each scale was initially tested in an unadjusted model; a second model adjusted for age, sex and diabetes duration; and a third model additionally adjusted for educational attainment. Models were tested for normal distribution of residuals. Further regression analysis was then undertaken using the same approach to determine the predictors of the 'Actively managing my health' scale of the HLQ. Residuals were approximately normally distributed, and tests for linearity were not statistically significant indicating that all associations were approximately linear. All statistical analyses were performed using SAS V.9.2. $p$ Values $<0.05$ were considered statistically significant.

\section{Ethics approval}

The study was approved by the Danish Data Protection Agency (protocol number H-2-2014-FSP38) and was undertaken in accordance with the Declaration of Helsinki. All participants provided written informed consent.

\section{Results}

Table 1 shows the characteristics of the study population and the mean HbAlc in related subgroups. Half of the 1399 respondents were women, and the majority had a tertiary education (table 1 . A group of 654 participants $(47 \%)$ were overweight or obese (BMI $>25)$, while 15 participants $(1 \%)$ were underweight $(\mathrm{BMI}<18.5)$. Of the respondents, 1075 (77\%) had an HbAlc level above $53 \mathrm{mmol} / \mathrm{mol}(7.0 \%)$. The highest HbAlc levels were present in those with lower educational attainment.

\section{Table 1 Characteristics of the study population and mean (SD) HbA1c}

\begin{tabular}{|c|c|c|c|c|}
\hline \multirow[b]{2}{*}{ Characteristic } & \multirow[b]{2}{*}{ No. } & \multirow[b]{2}{*}{$\%$} & \multicolumn{2}{|l|}{ Mean HbA1c } \\
\hline & & & $\mathrm{mmol} / \mathrm{mol}$ (SD) & $\%$ (SD) \\
\hline \multicolumn{5}{|l|}{ Sex } \\
\hline Male & 702 & 50.2 & $60(11.0)$ & $7.7(1.0)$ \\
\hline Female & 697 & 49.8 & $62(11.3)$ & $7.8(1.0)$ \\
\hline \multicolumn{5}{|l|}{ Age } \\
\hline 18-39years & 282 & 20.2 & $62(13.1)$ & $7.8(1.2)$ \\
\hline 40-59years & 560 & 40.0 & $62(11.5)$ & $7.8(1.1)$ \\
\hline $60-79$ years & 515 & 36.8 & $60(9.7)$ & $7.7(0.9)$ \\
\hline 80-91 years & 42 & 3.0 & 63 (10.9) & $7.9(1.0)$ \\
\hline \multicolumn{5}{|l|}{ Diabetes duration } \\
\hline 0-9years & 209 & 15.0 & $62(14.9)$ & $7.8(1.4)$ \\
\hline 10-19years & 309 & 22.1 & $62(10.7)$ & $7.9(1.0)$ \\
\hline 20-29years & 278 & 19.9 & $62(11.5)$ & $7.8(1.1)$ \\
\hline 30-39years & 285 & 20.4 & $61(9.9)$ & $7.7(0.9)$ \\
\hline 40-49years & 202 & 14.5 & $60(9.5)$ & $7.6(0.9)$ \\
\hline 50-75years & 115 & 8.2 & $58(8.9)$ & $7.5(0.8)$ \\
\hline \multicolumn{5}{|l|}{ Educational attainment } \\
\hline Undergoing education & 11 & 0.8 & $64(12.7)$ & $8.0(1.2)$ \\
\hline Primary or secondary & 66 & 4.9 & 65 (12.2) & $8.1(1.1)$ \\
\hline Postsecondary & 524 & 38.8 & $62(11.3)$ & $7.8(1.0)$ \\
\hline Short tertiary & 154 & 11.4 & $61(10.7)$ & $7.7(1.0)$ \\
\hline Bachelor or equivalent & 323 & 23.9 & $61(10.9)$ & $7.7(1.0)$ \\
\hline Master & 274 & 20.3 & $58(10.0)$ & $7.5(0.9)$ \\
\hline \multicolumn{5}{|l|}{$\mathrm{BMI}\left(\mathrm{kg} / \mathrm{m}^{2}\right)$} \\
\hline Under weight $(\mathrm{BMl}<18.5)$ & 15 & 1.1 & 69 (11.5) & $8.5(1.1)$ \\
\hline Normal weight (BMI 18.5-25) & 724 & 52.3 & $61(11.4)$ & $7.7(1.0)$ \\
\hline Overweight (BMI 25-30) & 485 & 35.0 & $61(10.9)$ & $7.7(1.0)$ \\
\hline Obese (BMl>30) & 160 & 11.6 & $63(10.8)$ & $7.9(1.0)$ \\
\hline All participants & 1399 & 100.0 & $61(11.2)$ & $7.8(1.0)$ \\
\hline
\end{tabular}

BMI, body mass index. 


\begin{tabular}{llll}
\hline Table 2 Distribution of HLQ scores & & & \\
\hline Scale & Range & Mean score & SD \\
\hline 1: Feeling understood and supported by healthcare providers & $1-4$ & 2.98 & 0.61 \\
\hline 2: Having sufficient information to manage health & $1-4$ & 3.07 & 0.49 \\
\hline 3: Actively managing my health & $1-4$ & 2.94 & 0.52 \\
\hline 4: Social support for health & $1-4$ & 2.96 & 0.59 \\
\hline 5: Appraisal of health information & $1-4$ & 2.77 & 0.54 \\
\hline 6: Ability to actively engage with healthcare providers & $1-5$ & 3.87 & 0.61 \\
\hline 7: Navigating the healthcare system & $1-5$ & 3.54 & 0.62 \\
\hline 8: Ability to find good health information & $1-5$ & 3.87 & 0.59 \\
\hline 9: Understanding health information well enough to know what to do & $1-5$ & 3.90 & 0.57 \\
\hline
\end{tabular}

HLQ, Health Literacy Questionnaire.

According to the available electronic patient record data, people who did not respond to the questionnaire were significantly more likely to be younger (mean age: 46 vs 54 ), to be male ( $58 \%$ vs $50 \%$ ), to have shorter diabetes duration (mean years: 22 vs 25), and had lower HbAlc level (mean: 65 vs $61 \mathrm{mmol} / \mathrm{mol}$ ) (data not shown).

Table 2 shows the distribution of HLQ scores and mean score in each domain. Relatively low scores of health literacy were observed in the domains 'Appraisal of health information' and 'Navigating the healthcare system'. The scores across domains are not directly comparable due to differences in numbers of response categories and different difficulty levels of the included items.

Table 3 shows the associations between HLQ domain scores and HbAlc level. Higher HLQ scores were significantly associated with lower levels of HbAlc in all domains except in 'Feeling understood and supported by healthcare providers'. Those results remained significant in unadjusted as well as analyses adjusted for age, sex, diabetes duration and educational attainment. A particular strong association was observed between high scores and the domain 'Actively managing my health' and low levels of HbAlc ( $b=-4.95,95 \%$ CI -6.06 to -3.84$)$. Moreover, when combining all HLQ scales into one mutually adjusted regression model, only the association between high score on 'Actively managing my health' and low HbA1c level was statistically significant (data not shown).

This analysis was repeated by examining the association within each educational group (table 4). This confirmed that high level of 'Actively managing my health' was associated with low HbA1c for each level of educational attainment.

However, the domain 'Actively managing my health' is a consistently robust predictor of $\mathrm{HbAlc}$, as these items/ this domain reflect whether an individual is a more active self-manager of their diabetes. Therefore, we examined the relationship between the other domains in the heath literacy measure and active management, as this would provide insights into what facets of health literacy are likely to be most important for diabetes services. In an adjusted model, three domains were significantly predictive of 'Actively managing my health': 'Having sufficient information to manage health' ( $\mathrm{b}=0.21)$, 'Social support for health' $(b=0.11)$, and 'Appraisal of health information' $(b=0.40)$. To check if these associations are consistent across educational groups, regressions were run separately for each level of education (table 5). All three measures were largely predictive of 'Actively managing my health' across four education groups. In all education attainment groups, 'Appraisal of health information' was the strongest and most consistent predictor of 'Actively managing my health'. Approximately $10 \%$ of participants, relatively consistently across education groups, did not agree that they could appraise health information. Similarly, $10 \%$ of respondents indicated that they were not able to understand health information. This estimate showed substantial variation across educational groups, with up to $23 \%$ of the lowest education group struggling to understand health information.

We also stratified the data on diabetes duration (0-10 years; $10-30$ years; $30+$ years) and tested the associations in each stratum. Overall associations were persistent across all strata. However, the analyses showed a tendency to stronger associations among newly diagnosed people (data not shown).

\section{DISCUSSION AND CONCLUSION}

In this large population of people with type 1 diabetes, we found that across all levels of educational attainment and diabetes duration, difficulty in appraising health information is a robust predictor of effectively managing diabetes in terms of HbA1c. In addition, understanding health information and getting support for health were also significant predictors of active management of health in four of the five education attainment groups. The strength of these associations across groups of different educational attainment indicates that there is a path from these skills to active self-management and diabetes outcomes (figure 1), which points to a key issue for diabetes care professionals.

Given the developing context for type 1 diabetes care, such new technologies for monitoring blood glucose and medication administration, it would seem that the ability 
Table 3 Linear regression results of associations between HLQ scale scores and HbA1c. Unadjusted and adjusted models representing the estimated difference in HbA1c for a one unit change in HLQ score. Values shown in bold are statistically significant

\begin{tabular}{|c|c|c|c|c|c|}
\hline Domain & Adj. R2 & $\begin{array}{l}\text { Regression } \\
\text { coefficient }\end{array}$ & SE & $(95 \% \mathrm{Cl})$ & p Value \\
\hline \multicolumn{6}{|c|}{$\begin{array}{l}\text { 1. Feeling understood and supported by healthcare } \\
\text { providers }\end{array}$} \\
\hline Model 1 & 0.000 & 0.00 & 0.49 & $(-0.95$ to 0.96$)$ & 0.998 \\
\hline Model 2 & 0.012 & 0.14 & 0.49 & $(-0.82$ to 1.11$)$ & 0.769 \\
\hline Model 3 & 0.035 & 0.27 & 0.49 & (-0.69 to 1.22$)$ & 0.486 \\
\hline \multicolumn{6}{|c|}{$\begin{array}{l}\text { 2. Having sufficient information to manage my } \\
\text { health }\end{array}$} \\
\hline Model 1 & 0.012 & -2.56 & 0.61 & $(-3.75$ to -1.36$)$ & $<0.001$ \\
\hline Model 2 & 0.023 & -2.45 & 0.61 & $(-3.64$ to -1.25$)$ & $<0.001$ \\
\hline Model 3 & 0.041 & -2.07 & 0.61 & $(-3.26$ to -0.88$)$ & $<0.001$ \\
\hline \multicolumn{6}{|c|}{ 3. Actively managing my health } \\
\hline Model 1 & 0.061 & -5.34 & 0.56 & $(-6.45$ to -4.25$)$ & $<0.001$ \\
\hline Model 2 & 0.073 & -5.34 & 0.56 & $(-6.44$ to -4.23$)$ & $<0.001$ \\
\hline Model 3 & 0.086 & -4.95 & 0.57 & $(-6.06$ to -3.84$)$ & $<0.001$ \\
\hline \multicolumn{6}{|c|}{ 4. Social support for health } \\
\hline Model 1 & 0.003 & -1.28 & 0.51 & $(-2.28$ to -0.03$)$ & 0.012 \\
\hline Model 2 & 0.016 & -1.17 & 0.51 & $(-2.16$ to -0.18$)$ & 0.021 \\
\hline Model 3 & 0.038 & -1.05 & 0.50 & $(-2.03$ to -0.07$)$ & 0.029 \\
\hline \multicolumn{6}{|c|}{ 5. Appraisal of health information } \\
\hline Model 1 & 0.008 & -1.99 & 0.56 & $(-3.08$ to -0.90$)$ & $<0.001$ \\
\hline Model 2 & 0.022 & -2.05 & 0.56 & $(-3.14$ to -0.96$)$ & $<0.001$ \\
\hline Model 3 & 0.040 & -1.51 & 0.56 & $(-2.61$ to -0.42$)$ & 0.005 \\
\hline \multicolumn{6}{|c|}{$\begin{array}{l}\text { 6: Ability to actively engage with healthcare } \\
\text { providers }\end{array}$} \\
\hline Model 1 & 0.013 & -2.16 & 0.49 & $(-3.11$ to -1.20$)$ & $<0.001$ \\
\hline Model 2 & 0.024 & -1.98 & 0.49 & $(-2.94$ to -1.24$)$ & $<0.001$ \\
\hline Model 3 & 0.043 & -1.67 & 0.49 & $(-2.63$ to -0.72$)$ & $<0.001$ \\
\hline \multicolumn{6}{|c|}{ 7. Navigating the healthcare system } \\
\hline Model 1 & 0.011 & -1.90 & 0.48 & $(-2.84$ to -0.96$)$ & $<0.001$ \\
\hline Model 2 & 0.021 & -1.70 & 0.48 & $(-2.65$ to -0.76$)$ & $<0.001$ \\
\hline Model 3 & 0.039 & -1.27 & 0.49 & $(-2.22$ to -0.32$)$ & 0.006 \\
\hline \multicolumn{6}{|c|}{ 8. Ability to find good health information } \\
\hline Model 1 & 0.013 & -2.17 & 0.50 & $(-3.15$ to -1.19$)$ & $<0.001$ \\
\hline Model 2 & 0.026 & -2.32 & 0.50 & $(-3.31$ to -1.34$)$ & $<0.001$ \\
\hline Model 3 & 0.041 & -1.71 & 0.51 & $(-2.72$ to -0.70$)$ & $<0.001$ \\
\hline \multicolumn{6}{|c|}{$\begin{array}{l}\text { 9. Understanding health information well enough to } \\
\text { know what to do }\end{array}$} \\
\hline Model 1 & 0.021 & -2.86 & 0.52 & $(-3.89$ to -1.84$)$ & $<0.001$ \\
\hline Model 2 & 0.032 & -2.87 & 0.52 & $(-3.90$ to -1.85$)$ & $<0.001$ \\
\hline Model 3 & 0.045 & -2.19 & 0.54 & $(-3.25$ to -1.13$)$ & $<0.001$ \\
\hline
\end{tabular}

Model 3: adjusted for sex, age, diabetes duration, and educational attainment.

Model 2: adjusted for sex, age, and diabetes duration.

Model 1: unadjusted.

HLQ, Health Literacy Questionnaire. 
Table 4 Predictors of 'Actively managing my health' stratified by educational attainment. Results from adjusted linear regressions $(n=1333)$

\begin{tabular}{|c|c|c|c|c|c|}
\hline Educational attainment & Domain & $\begin{array}{l}\text { Regression } \\
\text { coefficient }\end{array}$ & SE & $95 \% \mathrm{Cls}$ & p Value \\
\hline \multirow[t]{3}{*}{$\begin{array}{l}\text { Primary or secondary } \\
(\mathrm{n}=241)\end{array}$} & $\begin{array}{l}\text { Having sufficient information to } \\
\text { manage my health }\end{array}$ & 0.034 & 0.069 & $(-0.102$ to 0.169$)$ & 0.627 \\
\hline & Social support for health & 0.156 & 0.053 & (0.052 to 0.259$)$ & 0.003 \\
\hline & Appraisal of health information & 0.435 & 0.058 & (0.320 to 0.549$)$ & $<0.001$ \\
\hline \multirow{3}{*}{$\begin{array}{l}\text { Postsecondary } \\
\text { (eg, carpenter and farmer; } \\
\mathrm{n}=381 \text { ) }\end{array}$} & $\begin{array}{l}\text { Having sufficient information to } \\
\text { manage my health }\end{array}$ & 0.251 & 0.056 & (0.140 to 0.361$)$ & $<0.001$ \\
\hline & Social support for health & 0.053 & 0.044 & $(-0.033$ to 0.139$)$ & 0.228 \\
\hline & Appraisal of health information & 0.404 & 0.051 & (0.305 to 0.504$)$ & $<0.001$ \\
\hline \multirow{3}{*}{$\begin{array}{l}\text { Tertiary (non-master) } \\
\text { (eg, nurse and policeman; } \\
n=447 \text { ) }\end{array}$} & $\begin{array}{l}\text { Having sufficient information to } \\
\text { manage my health }\end{array}$ & 0.313 & 0.049 & (0.216 to 0.410$)$ & $<0.001$ \\
\hline & Social support for health & 0.087 & 0.039 & (0.010 to 0.164$)$ & 0.026 \\
\hline & Appraisal of health information & 0.372 & 0.042 & (0.290 to 0.454$)$ & $<0.001$ \\
\hline \multirow{3}{*}{$\begin{array}{l}\text { Master } \\
\text { (eg, engineer and lawyer; } \\
n=266 \text { ) }\end{array}$} & $\begin{array}{l}\text { Having sufficient information to } \\
\text { manage my health }\end{array}$ & 0.168 & 0.054 & (0.061 to 0.274$)$ & 0.002 \\
\hline & Social support for health & 0.176 & 0.045 & (0.087 to 0.265$)$ & $<0.001$ \\
\hline & Appraisal of health information & 0.385 & 0.046 & (0.296 to 0.475$)$ & $<0.001$ \\
\hline
\end{tabular}

to understand and appraise health information is critical. If we further add the challenges arising from conflicting messages and information provided on the web and other sources $^{22}$ as well as from different health professionals, ${ }^{23}$ then the importance of understanding and appraising health information becomes even more relevant. If more than $10 \%$ of the respondents in the current study, where higher educational groups were over-represented, struggle with these skills, this is an issue that needs to be addressed. Our finding emphasizes two key issues for type 1 diabetes care. The first is the need to ensure that resources provided match people's literacy and health literacy capabilities. As researchers continue to document the failure of educational resources to meet these needs or standards, ${ }^{4}$ this is clearly a priority for diabetes care teams to address. In addition, if individuals are struggling with appraising health information, diabetes educational services in all their forms, from one-on-one consultations through to structured group program, need to engage individuals with pedagogical approaches that are responsive to the individual health literacy skills and capabilities. Second, one might consider providing basic health literacy program for people with diabetes.
This would not be program focused on diabetes management information, skills and competencies as such, but rather focused on the basic skills and capabilities needed to understand and appraise health information. This in itself may result in substantial health gains for those who are clearly struggling to understand how to manage their diabetes most effectively.

Health literacy is also related to the health and information demands of affected people. As diabetes progresses, the need for information, support, and navigation of the healthcare system increases. However, people with type 1 diabetes may also improve their health competencies following their diagnosis resulting in improved HLQ scores. Our analyses included adjustment for age and diabetes duration, as well as sex and education, which did not substantively change the estimates. This could either mean that the above-mentioned mechanisms were not present in our study population or that they were compensating for each other, remaining invisible.

A strength of this study is the large sample. The medically certified data on HbAlc allowed for analyses of clinical relevance, which could not have been obtained from self-reported data. Moreover, use of medical records

Table 5 Associations between 'Actively managing my health' and HbA1c stratified by educational attainment. Results from linear regressions $(n=1333)$

\begin{tabular}{|c|c|c|c|c|}
\hline Educational attainment & Regression coefficient & SE & $95 \%$ Cls & p Value \\
\hline Primary or secondary & -7.0 & 1.54 & $(-10.02$ to -4.07$)$ & $<0.001$ \\
\hline Postsecondary (eg, carpenter and farmer) & -5.9 & 1.07 & $(-7.99$ to -3.86$)$ & $<0.001$ \\
\hline $\begin{array}{l}\text { Tertiary (non-master) } \\
\text { (eg, nurse and policeman) }\end{array}$ & -2.7 & 0.95 & $(-4.56$ to -0.82$)$ & 0.005 \\
\hline Master (eg, engineer and lawyer) & -3.9 & 1.19 & $(-6.24$ to -1.55$)$ & 0.001 \\
\hline
\end{tabular}




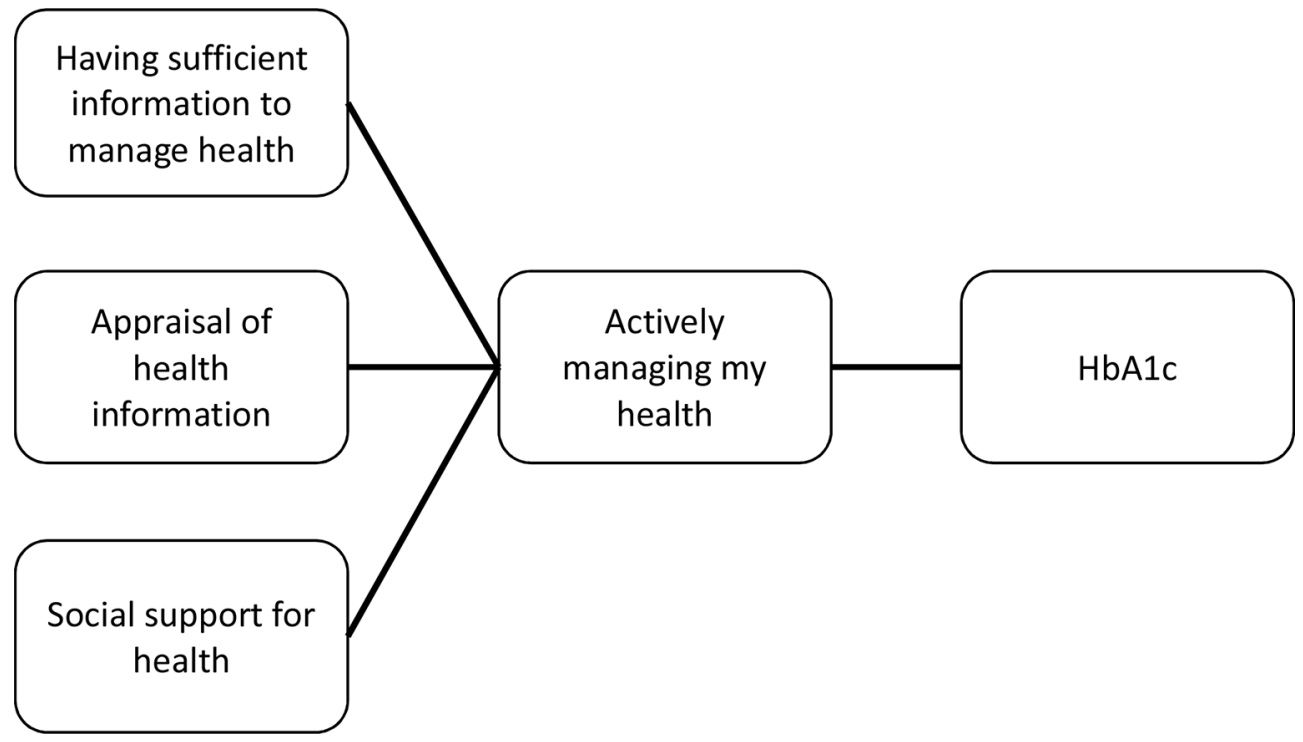

Figure 1 Suggested pathways from health literacy domains to diabetes outcomes

provided data free of bias related to self-reporting. This is a particular strength in studies of health literacy, as health literacy may influence self-reported health information of morbidity and introduce non-differential bias, that is, inaccurate reporting of morbidity depending on the level of health literacy.

A limitation of this study was the moderately low response rate. As often seen in questionnaire-based research, non-responders tend to be relatively younger, male and with lower HbA1c. ${ }^{24}$ We sought to include all people registered at the clinic in the study regardless of factors such as age, vision impairment, language barriers, and disease status. Even though assistance was offered to people with vision impairment, disadvantaged participants, including people with low literacy, may have been less likely to take part. While the findings are expected to have internal validity, care needs to be taken when extrapolating the results to wider populations, particularly overestimation of health literacy may be a risk. Self-reporting, which can be regarded as a limitation, was used to measure health literacy and other variables including education. While some aspects of health literacy can be measured using direct testing, namely functional health literacy (eg, health-related reading ability), many aspects concern a person's own perception and experiences related to their ability, and of interactions with healthcare personal and the healthcare system, cannot be obtained without self-reports. The HLQ has been shown to have strong psychometric properties and to be useful in studies of health outcomes also in a Danish setting. ${ }^{195} 26$ The accuracy of our measurement of educational attainment was also potentially reduced by self-report. Due to the large age span among the participants and the secular increase in education level in the national population, a correlation between age and educational attainment is expected. Moreover, as categorization of education results is a substantial simplification, the full impact of education may not be fully represented in our analysis. Caution should be taken when interpreting the adjusted estimates as they may be influenced by residual confounding of educational effects despite the attempt to adjust for this. Regardless of these limitations, the comprehensive data and clinically certified outcomes were useful in establishing associations between health literacy and HbAlc level.

To our knowledge, this is the first study to analyze the association between comprehensive health literacy and HbA1c level in a large population of people with type 1 diabetes. The findings suggest a range of potential intervention points to improve services for people with type 1 diabetes and for improving self-management support strategies. Improvements in health literacy among disadvantaged groups have the potential to improve HbAlc level and prevent future mortality and morbidity related to type 1 diabetes.

In conclusion, this study provides evidence for a linear association between health literacy and HbAlc level in people with type 1 diabetes, regardless of their educational background. The HLQ identifies potential targets for improving diabetes management program, including skills development (eg, support for active self-management and having and appraising health information) as well as indicators for improving the responsiveness of services provided to people with type 1 diabetes (eg, quality and availability of materials). Development and implementation of tailored interventions to improve health literacy are likely to improve future diabetes management.

Contributors Supervised by LJ and IW; ALFR prepared data and carried out preanalysis. All authors contributed to the design of the study. KO completed the analyses and drafted the manuscript. All authors contributed to the final version of the manuscript.

Competing interests None declared. 
Patient consent Detail has been removed from this case description/these case descriptions to ensure anonymity. The editors and reviewers have seen the detailed information available and are satisfied that the information backs up the case the authors are making.

Ethics approval The Danish Data Protection Agency.

Provenance and peer review Not commissioned; externally peer reviewed.

Open Access This is an Open Access article distributed in accordance with the Creative Commons Attribution Non Commercial (CC BY-NC 4.0) license, which permits others to distribute, remix, adapt, build upon this work non-commercially, and license their derivative works on different terms, provided the original work is properly cited and the use is non-commercial. See: http://creativecommons.org/ licenses/by-nc/4.0/

(C) Article author(s) (or their employer(s) unless otherwise stated in the text of the article) 2017. All rights reserved. No commercial use is permitted unless otherwise expressly granted.

\section{REFERENCES}

1. Ahola AJ, Groop PH. Barriers to self-management of diabetes. Diabet Med 2013;30:413-20.

2. Cerna L, Maresova P. Patients' attitudes to the use of modern technologies in the treatment of diabetes. Patient Prefer Adherence 2016;10:1869-79.

3. Kaufman N. Information Technology in the Service of Diabetes Prevention and Treatment. Int J Clin Pract 2011;65:47-54

4. Hutchinson N, Baird GL, Garg M. Examining the Reading Level of Internet Medical Information for Common Internal Medicine Diagnoses. Am J Med 2016;129:637-9.

5. Nutbeam D, Glossary HPHealth Promot Int 1998;13:349-64.

6. Al Sayah F, Majumdar SR, Williams B, et al. Health literacy and health outcomes in diabetes: a systematic review. J Gen Intern Med 2013;28:444-52.

7. Bailey SC, Brega AG, Crutchfield TM, et al. Update on health literacy and diabetes. Diabetes Educ 2014;40:581-604.

8. Fransen MP, von Wagner C, Essink-Bot ML. Diabetes selfmanagement in patients with low health literacy: ordering findings from literature in a health literacy framework. Patient Educ Couns 2012;88:44-53.

9. van der Heide I, Wang J, Droomers M, et al. The relationship between health, education, and health literacy: results from the Dutch Adult Literacy and Life Skills Survey. J Health Commun 2013;18:172-84.

10. Brega AG, Ang A, Vega W, et al. Mechanisms underlying the relationship between health literacy and glycemic control in American Indians and Alaska Natives. Patient Educ Couns 2012;88:61-8.
11. Woodard LD, Landrum CR, Amspoker AB, et al. Interaction between functional health literacy, patient activation, and glycemic control. Patient Prefer Adherence 2014;8:1019-24.

12. Cavanaugh $\mathrm{K}$, Huizinga MM, Wallston $\mathrm{KA}$, et al. Association of numeracy and diabetes control. Ann Intern Med 2008;148:737-U40.

13. Gerber BS, Pagcatipunan M, Smith EV, et al. The assessment of diabetes knowledge and self-efficacy in a diverse population using Rasch measurement. J Appl Meas 2006;7:55-73.

14. Morris NS, MacLean CD, Littenberg B. Literacy and health outcomes: a cross-sectional study in 1002 adults with diabetes. BMC Fam Pract 2006;7:49.

15. Kim S, Love F, Quistberg DA, et al. Association of health literacy with self-management behavior in patients with diabetes. Diabetes Care 2004;27:2980-2.

16. Mancuso JM. Impact of health literacy and patient trust on glycemic control in an urban USA population. Nurs Health Sci 2010;12:94-104.

17. Friis K, Lasgaard M, Rowlands G, et al. Health Literacy Mediates the Relationship Between Educational Attainment and Health Behavior: A Danish Population-Based Study. J Health Commun 2016;21:54-60.

18. Maindal HT, Kayser L, Norgaard O, et al. Cultural adaptation and validation of the Health Literacy Questionnaire (HLQ): robust ninedimension Danish language confirmatory factor model. Springerplus 2016;5:1232.

19. Osborne RH, Batterham RW, Elsworth GR, et al. The grounded psychometric development and initial validation of the Health Literacy Questionnaire (HLQ). BMC Public Health 2013;13:658.

20. Beauchamp A, Buchbinder R, Dodson S, et al. Distribution of health literacy strengths and weaknesses across socio-demographic groups: a cross-sectional survey using the Health Literacy Questionnaire (HLQ). BMC Public Health 2015;15:678.

21. Hill NR, Peters CJ, Thompson RJ, et al. Cyclical variation in HbA1c values during the year: clinical and research implications. Diabetes Care 2013;36:e175-e176.

22. Carpenter DM, Elstad EA, Blalock SJ, et al. Conflicting medication information: prevalence, sources, and relationship to medication adherence. J Health Commun 2014;19:67-81.

23. Swift PG, Skinner TC, de Beaufort CE, et al. Target setting in intensive insulin management is associated with metabolic control: the Hvidoere childhood diabetes study group centre differences study 2005. Pediatr Diabetes 2010;11:271-8.

24. Leeuw ED, Hox JJ, Dillman DA. European Association of Methodology. International handbook of survey methodology. New York; London: Lawrence Erlbaum Associates 2008;549.

25. Kayser L, Hansen-Nord NS, Osborne RH, et al. Responses and relationship dynamics of men and their spouses during active surveillance for prostate cancer: health literacy as an inquiry framework. BMC Public Health 2015;15:741.

26. Friis $\mathrm{K}$, Lasgaard $\mathrm{M}$, Osborne $\mathrm{RH}$, et al. Gaps in understanding health and engagement with healthcare providers across common long-term conditions: a population survey of health literacy in 29473 Danish citizens. BMJ Open 2016;6:e009627. 